\title{
Analysis of surface settlement control with shield tunneling method
}

\author{
Caihui Zhu ${ }^{\text {i) }}$ \\ i) D . E ., Institute of Geotechnical Engineering, Xi'an University of Technology \\ 5 South Jinhua Road, Xi'an, Shaanxi, 710048, P.R. China
}

\begin{abstract}
The surface settlement (SS) induced by shield tunneling method can be predicted using the modified Peck formula based on the modified gap parameters proposed in this work. The modified gap parameters considered shield tunneling parameters (STPs) can be expressed with the support pressure ratio of shield $(\lambda)$, fill rate of grouting $(\beta)$, and eccentricity ratio of shield $(\kappa)$. Based on the actual cases of the Xi'an subway line 2 in China, the results of sensitivity and back analysis of STPs show that $\beta$ has a minimal effect on SS, $\lambda$ has a significant influence on SS, and $\kappa$ has the maximum effect on SS. The maximum SS and surface curvature due to shield tunneling are be considered to control the permitted deformation according to the Chinese standards. Thus the control standards of STPs are obtained and suggested through the back analysis of damage classification by using the modified Peck formula.
\end{abstract}

Keywords: surface settlement control, shield tunneling method, gap parameter, modified Peck formula

\section{INTRODUCTION}

Methods for analyzing and predicting surface settlement, such as the empirical method, analytical solution, semi-analytical numerical method, model experiment analysis, numerical analysis method, artificial neural network method, modern cybernetics method, and time series analysis method, had facilitated numerous research achievements. The most commonly used method is the empirical method.

Peck (1969) first proposed that surface settlement (SS) trough was in accordance with normal distribution at the International Conference on Soil Mechanics. Schmidt (1969), Attewell et al. (1978a, 1978b, 1982), and Rankin (1988) then published articles to support the Peck formula. Attewell and Woodman (1982) presented a cumulative probability curve to describe the longitudinal settlement. Two important parameters in the Peck formula are settlement trough width and ground volume loss. Ground volume loss is concerned with the engineering geology conditions, hydrogeological conditions, tunnel construction methods, construction technique skills, and project management experiences, all of which were studied by Burland (2001), Attewell, P.B. (1986), Broms (1967), and Glossop (1978). Moreover, O'Reilly, et al. (1982) established a method to compute for the ground horizontal displacement with the assumption that the strata displacement vector pointed toward the tunnel center. Mair, et al. (1993) established a formula to compute for deep-layer strata displacement. Celestino, et al. (2000) presented a highly flexible plug-shaped curve to predict the SS. Yang et al. (1998) used stochastic medium theory to predict the SS through subway construction using the shield method.

The final reason for SS is that shield construction disturbed the soil stratum. Mair et al. $(1993,1997)$ used in-situ tests, laboratory experiments, and theoretical analyses to study the failure mechanism and disturbed areas of the soil surrounding the tunnel. The results showed that the SS was attributable to the variability of soil properties because owing to extrusion, loosening, loading, uploading, as well as rise and fall of pore water pressure with the shield method. However, the shield construction parameters were difficult to quantify reasonably.

To predict SS by considering shield construction, Rowe et al. (1983) proposed a famous gap parameter concept, whereas Lee et al. (1992) presented the theoretical calculation formula for gap parameters. Subsequently, Lo et al. (1984b), and Verruijt and Booker(1996) established their analytic formulas to predict SS. According to these analytic formulas, Loganathan and Poulos (1998) redefined the coefficient of strata volume loss and suggested a modified formula. However, the parameter of workmanship in the gap parameter formula was difficult to determine.

Considerable research results have been obtained on the prediction methods for SS induced by shield tunneling construction. However, studies on the control standards of SS the shield tunneling construction 
technology remain insufficient.

This study aims to predict the SS attributed to shield tunneling construction by using a modified Peck formula method and then proposes the control standards for shield tunneling technology. Based on the modified gap parameters and measurements, the sensitivity analyses of SS and its prediction using Peck formula are presented. The control standards of shield tunneling are obtained through back analysis with the damage classifications of masonry structures.

\section{METHODS}

\subsection{Introduction of gap parameter}

To analyze the ground movements attributed to shield tunneling, many theoretical formulas and simplified models have been proposed by scholars. Rowe et al. (1983) are best known for their theories on the gap parameter for the calculation of the crown deformation of tunnels and ground SS in clays under undrained conditions. These theories included the three-dimensional elastoplastic deformation at the tunnel face, the effect of the workmanship of the shield tunneling, and the physical gap or the geometry of the shield and lining system. These three factors are equivalent to a two-dimensional gap, as shown in Fig. 1

According to the theoretical analysis model, the gap parameter was proposed by Lee et al. (1992). This parameter can be expressed by the following equation:

$$
g=G_{\mathrm{p}}+U_{e, p}^{*}+w
$$

where $U_{e, p}^{*}$ represents the equivalent of the three-dimensional elastoplastic deformation at the tunnel face. The term $w$ considers the quality of workmanship and is induced by the pitch and yaw of the tunneling machine, the effectiveness of tail void grouting, the rate of soil deformation, and human error. The physical gap $\left(G_{\mathrm{p}}\right)$ represents the geometric clearance between the outer skin of the shield and the lining. This parameter considers the thickness of the tailpiece $(\Delta)$ and the clearance required for the erection of the lining $(\delta)$.

The ratio of the vertical deformation at the crown attributed to 3D movements $\left(U_{e, p}^{*}\right)$ into the heading can reach approximately 0.25 of the radial displacement $\left(U_{i}\right)$ around the tunnel. The plane strain solution for $U_{e, p}^{*}$ is given by Lo et al. (1984b) and Lee as follows:

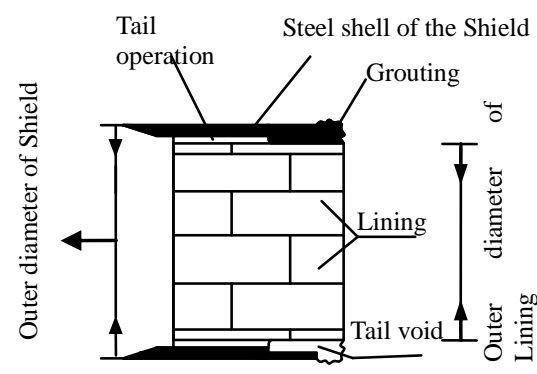

$$
U_{e, p}^{*}=\frac{U_{i}}{4}=(R / 4)\left[1-\sqrt{\left\{\frac{1}{1+\frac{2\left(1+v_{u}\right) c_{u}\left[\exp \left(\frac{P_{0}-P_{i}-c_{u}}{2 c_{u}}\right)\right]_{u}}{2}}\right]}\right]
$$

where $P_{0}$ is the effective hydrostatic overburden pressure at the tunnel face; $P_{\mathrm{i}}$ is the internal support pressure; $\mathrm{R}$ is the outer radius of the tunnel lining; and $E_{\mathrm{u}}, c_{\mathrm{u}}$, and $v_{\mathrm{u}}$ are the modulus of deformation, cohesion, and Poisson ratio under undrained conditions, respectively.

Eq. (1) shows the influence factors on the gap parameter attributed to the shield workmanship, support pressure at the tunnel face, and physical gap. However, the quality of workmanship is difficult to determine. Thus, based on the factual engineering, a modified method for calculating the gap parameter is proposed with the introduction of the fill rate of grouting $(\beta)$, the shield eccentricity ratio attributed to the over break of the shield machine $(\kappa)$, and the support pressure ratio at the tunnel face $(\lambda)$. The solution to the above parameters is described in the succeeding sections.

\subsection{Fill rate of grouting $\beta$}

Theoretically, the shield tail grouting should fully fill the physical gap. According to engineering experiences, the volume ratio range of grouting per unit length to the physical gap is between 1.2 and 2.5 , such that SS occurs because of the volume loss of the stratum. However, the elimination effect of the grouting for the gap is difficult to determine for several reasons: (1) irregular grouting attributed to the non-uniform stratum, (2) grouting losses during transport and unstable grouting pressure, and (3) volume shrinkage of grouting because of the grouting hardening. Suppose that the grouting fill ratio of physical gap is $\beta$, the ratio of which is between $60 \%$ and $90 \%$, the thickness of the unfilled gap of the tunnel crown can be expressed according to the concept of the gap parameter as follows:

$$
g_{1}=(1-\beta) G_{\mathrm{p}}=(1-\beta)(2 \Delta+\delta)
$$

\subsection{Eccentricity ratio $\kappa$}

For the uneven stratum, the shield machine should be rectified to ensure that the shield and the tunnel retain the same axial line when the shield pitches and yaws.

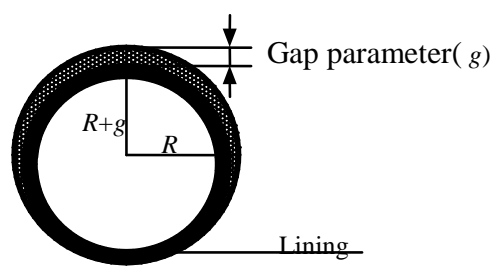

Fig. 1 Definition of gap parameters 
Thus, over excavation of the tunnel occurs, and SS is generated if the shield exhibits unreasonable performance and is affected by human error. We suppose that the main body eccentricity of the shield machine is $\delta$, which can be measured from the shield equipment, as shown in Fig. 2.

The eccentricity ratio of the shield head $\kappa$ can be expressed as:

$$
\delta=\kappa L=L \tan \alpha=\sqrt{S_{\mathrm{H}}^{2}+S_{\mathrm{V}}^{2}}
$$

where $S_{\mathrm{H}}$ and $S_{\mathrm{V}}$ respectively denote the horizontal and vertical displacement of the monitoring point, $L$ is the main body length of the shield machine, and $\alpha$ is the eccentricity angle. In the actual project, the eccentricity ratio of the shield head $\kappa$ is between $0.0 \%$ and $4.0 \%$.

The area of over excavation region $S_{\mathrm{e}}$ can be expressed as

$$
S_{\mathrm{e}}=(\pi-2 \theta) R^{2}+\delta R \sin \theta=\pi\left(R^{\prime 2}-R^{2}\right)
$$

where the term $\theta$ is the angle of the main body eccentricity of the shield machine, which can be expressed as: $\theta=\arccos (\delta / 2 R)$; and radius $R$ is the gap attributed to over excavation.

Given that a gap induced by over excavation may be generated anywhere around the outer radius face of the lining, we assume that the gap is evenly distributed over the lining, and its thickness $\Delta_{2}$ is expressed as

$$
\Delta_{2}=\mathrm{R}^{\prime}-\mathrm{R}=\sqrt{\left(2-\frac{2 \theta}{\pi}\right) \mathrm{R}^{2}+\frac{\delta \mathrm{R} \sin \theta}{\pi}}-\mathrm{R}
$$

The gap parameter $\left(g_{2}\right)$ of the tunnel crown induced by shield over excavation can be expressed as

$$
g_{2}=2 \Delta_{2}=2\left(\sqrt{2 \mathrm{R}^{2}\left(1-\frac{1}{\pi} \arccos \frac{k L}{2 R}\right)+\frac{k L}{2 \pi} \sqrt{4 \mathrm{R}^{2}-k^{2} L^{2}}}-\mathrm{R}\right)
$$

\subsection{Support pressure ratio $\lambda$}

With the earth pressure balance method, the soil stores pressure, or the support pressure $\left(P_{i}\right)$ of the shield should be dynamically consistent with the in-situ stress of the stratum. If the support pressure is less than the in-situ stress, SS or ground uplift occurs. According to Lee, et al. (1992) and Lo (1984b), the vertical elastoplastic deformation at the crown (or the gap parameter $g_{3}$ ) attributed to three-dimensional movements into the heading is associated with support pressure, which can be expressed as

$$
g_{3}=\frac{R}{4}\left[1-\sqrt{\left.\frac{1}{1+\frac{2\left(1+v_{\mathrm{u}}\right) c_{\mathrm{u}}\left[\exp \left(\frac{\left(\gamma H-P_{\mathrm{i}}\right) / c_{\mathrm{u}}-1}{2}\right)\right]_{\mathrm{u}}^{2}}{2}}\right]}\right]
$$

where $N$ is the deformation coefficient, which is associated with the stability of the tunnel face; and $P_{i}$ is the support pressure.

Suppose that the relation between support pressure and in-situ stress can be expressed as

$$
P_{i}=\lambda \gamma H
$$

where $\gamma$ is the average unit weight of the covered soil of the tunnel; $H$ is the buried depth of the tunnel center; and $\lambda$ is the support pressure ratio. The proposed parameter $\lambda$ shows the relationship between support pressure and in-situ lateral earth pressure, the value of which is between 0.0 and 1.0. The gap parameter attributed to inadequate support pressure can be expressed as:

$$
g_{3}=0.25 R\left[1-\sqrt{\frac{1}{1+\frac{2\left(1+v_{\mathrm{u}}\right) c_{\mathrm{u}}}{E_{\mathrm{u}}}\left[\exp \left(\frac{(1-\lambda) \gamma H-c_{\mathrm{u}}}{2 c_{\mathrm{u}}}\right)\right]^{2}}}\right]
$$

\subsection{Modified gap parameter}

According to the aforementioned gap parameters, the modified gap parameter can be expressed as follows:

$$
g=g_{1}+g_{2}+g_{3}
$$

\subsection{Modified Peck formula based on gap parameter and measurements}

Studies have shown that the volume loss and settlement trough of the stratum in the Peck formula are associated with the gap parameter and buried depth of the tunnel. Thus, the modified Peck formula can be expressed as

$$
S_{x}=S_{\max } \exp \left[-\frac{x^{2}}{2 i^{2}}\right]=\frac{\sqrt{\pi}\left(4 g R+g^{2}\right)}{4 \sqrt{2} K H} \exp \left[-\frac{x^{2}}{2(K H)^{2}}\right]
$$

where $g$ is the gap parameter, as shown in Eq. (1 1); $H$ is the buried depth of the tunnel; $x$ is the $\mathrm{h}$ orizontal displacement from the tunnel center; $i$ is $\mathrm{t}$ he settlement trough width, which is equal to $K H$; and $K$ is coefficient of the settlement trough width.

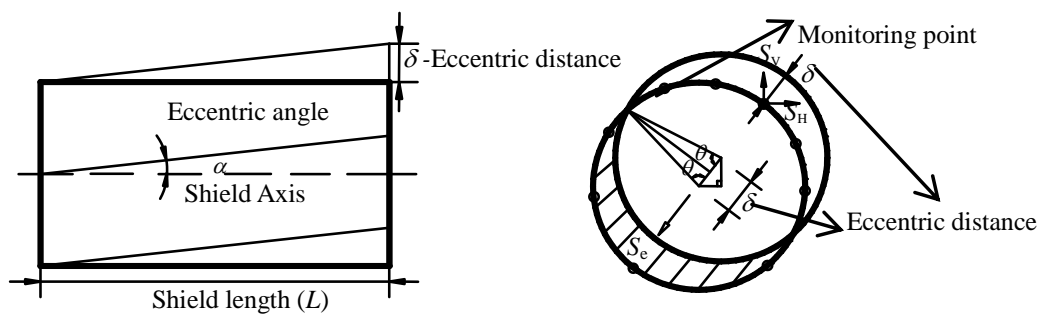

Fig. 2 Gap attributed to over excavation 
Based on the measurement data of typical sections of running tunnel from Zhang Jiabao to You Jiazhuang (Stake mark from $Y D K 4+313.504$ to $Y D K 5+552.016$ ) in Xi'an subway line No. 2, the monitoring section numbers are S1, S2, S3, S4, and S5. The SS curves are shown in Fig. 3 and are best fitted with Peck formula Eq. (12). The parameters of the Peck formula are shown in Table 1.

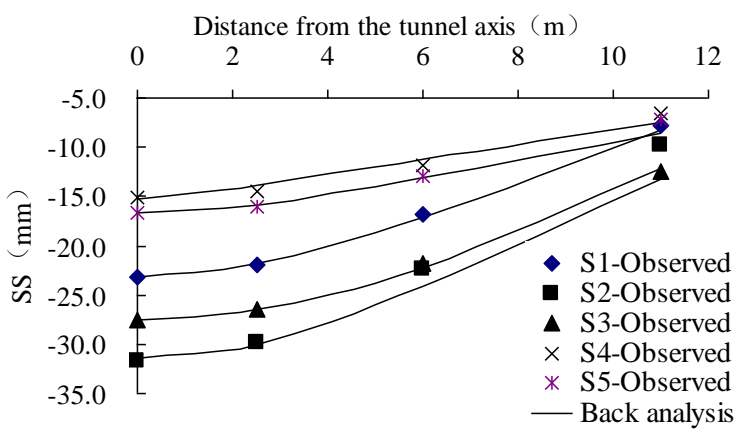

Fig. 3 Observed SS of different cross-section during shield tunneling

Table 1 Parameters of Peck curve based on observed data

\begin{tabular}{cccccc}
\hline Cross-section & $\mathrm{S} 1$ & $\mathrm{~S} 2$ & $\mathrm{~S} 3$ & $\mathrm{~S} 4$ & $\mathrm{~S} 5$ \\
\hline $\begin{array}{c}\text { parameters } \\
\text { Buried depth of } \\
\text { tunnel } H(\mathrm{~m})\end{array}$ & 16.5 & 18.0 & 18.5 & 19.0 & 21.0 \\
$\begin{array}{c}\text { Settlement trough } \\
\text { coefficient } K\end{array}$ & 0.45 & 0.47 & 0.48 & 0.51 & 0.51 \\
$\begin{array}{c}\text { Coefficient volume } \\
\text { loss } v_{1}(\%)\end{array}$ & 1.41 & 2.16 & 2.00 & 1.20 & 1.45 \\
\hline
\end{tabular}

It shows that the settlement trough coefficient of different sections varied from 0.45 to 0.51 , the average of which is equal to 0.49 . The coefficient of volume loss is between $1.20 \%$ and $2.16 \%$, whereas the average value is $1.64 \%$.

The calculation parameters are as follows:

(1) The outer diameter of the shield cutter $D$ is $6.25 \mathrm{~m}$, the outer diameter of the shield steel shell is $6.23 \mathrm{~m}$, the outer diameter of the lining is $6.0 \mathrm{~m}$, and the length of the shield $L$ is $8.0 \mathrm{~m}$. Thus, the physical gap $G_{\mathrm{p}}$ is $0.155 \mathrm{~m}$, and the thickness of the tailpiece $\Delta$ is $0.04 \mathrm{~m}$. The clearance required for the erection of the lining $\delta=0.075 \mathrm{~m}$.

(2) The mechanical parameters of the stratum above the tunnel are as follows: the modulus of deformation under undrained conditions $E_{\mathrm{u}}$ is $5.1 \mathrm{MPa}$, Poisson ratio $v_{\mathrm{u}}$ is 0.33 , natural bulk density $\gamma$ is $18.3 \mathrm{kN} / \mathrm{m}^{3}$, cohesion $c_{\mathrm{u}}$ is $28 \mathrm{kPa}$, and internal friction angle $\varphi$ is $25.0^{\circ}$.

The shield tunneling parameters (STPs) $\kappa_{\max }, \beta_{\min }$, and $\lambda_{\min }$ can be obtained through the back analysis method. The minimal value of support pressure ratio has to be between 0.693 and 0.771 , with an average value of 0.729 . The maximum value of fill rate of grouting is between 0.581 and 0.770 , with an average value of 0.682 . The minimal value of eccentricity ratio varies from $0.33 \%$ to $0.62 \%$, with an average value of $0.47 \%$.

\section{RESULTS AND DISCUSSION}

\subsection{Sensitivity analysis of the SS attributed to STPs}

To analyze quantitatively the influence on the SS attributed to the shield tunneling method, the three parameters $\beta, \kappa$, and $\lambda$ are introduced to the modified Peck formula Eq. (12). Three analytical solutions are given below.

(1) Support pressure ratio $\lambda$ is equal to $0.4,0.5,0.6$, $0.7,0.8,0.9$, and 1.0 , the fill rate of grouting $\beta$ is $100 \%$, and the eccentricity ratio $\kappa$ is $0.0 \%$;

(2) Fill rate of grouting $\beta$ is equal to $40 \%, 50 \%$, $60 \%, 70 \%, 80 \%, 90 \%$, and $100 \%$, the support pressure ratio $\lambda$ is $100 \%$, and the eccentricity ratio $\kappa$ is $0.0 \%$;

(3) Eccentricity ratio $\kappa$ is equal to $0.0 \%, 0.1 \%, 0.5 \%$, $1.0 \%, 2.0 \%, 3.0 \%$, and $5.0 \%$, the fill rate of grouting $\beta$ is $100 \%$, and the support pressure ratio $\lambda$ is $100 \%$.

The calculation parameters are derived from a certain running tunnel of Xi'an subway line No. 2. The average buried depth of the tunnel $H$ is $16.5 \mathrm{~m}$, the coefficient of settlement trough $K$ is 0.49 , and the other parameters are the same as presented in Section 2.6.

According to the above parameters, the relationship of the maximum settlement value with $\lambda, \beta$, and $\kappa$ is shown in Fig. 4. From the pictures, it can be seen that the parameter $\kappa$ is the most sensitive one, $\lambda$ is the middle one and the $\beta$ is the last one.

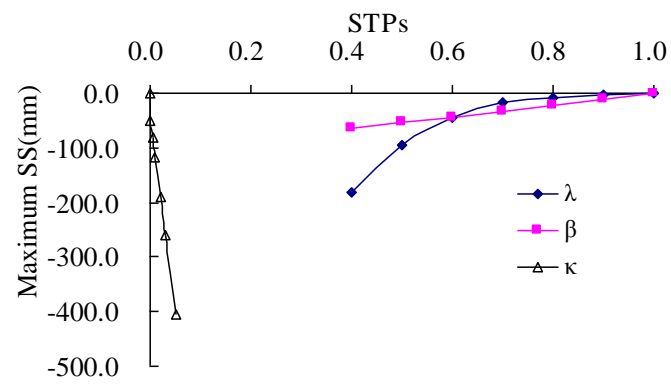

Fig. 4 Maximum SS under different STPs

\subsection{Back analysis of SS with STPs}

Based on another testing section of the running tunnel from Zhang Jiabao to You Jiazhuang (Stake mark from YDK4+439.204 to YDK5+485.316) of Xi'an subway line No. 2, the buried depth of the tunnel $H$ is $10.0 \mathrm{~m}$, the coefficient of the settlement trough $K$ is 0.49 , and the sizes of the shield and lining are equal to the previously mentioned values. The modulus of deformation $E_{\mathrm{u}}$ is $5.6 \mathrm{MPa}$, Poisson ratio $v_{\mathrm{u}}$ is 0.30 , natural bulk density $\gamma$ is $18.3 \mathrm{kN} / \mathrm{m}^{3}$, cohesion $c_{\mathrm{u}}$ is $24.0 \mathrm{kPa}$, and internal friction angle $\varphi$ is $13.6^{\circ}$. According to these parameters, the comparison figures between the SS prediction and the measurements are shown in Figs. 5. 
The SS predictions using lower limit SPT parameters were in good agreement with the measurements. The back analyses of the measured profile are shown in Fig. 5, which reveals that the SS may be in good agreement with the measurements only if $\lambda \geq 0.90, \beta \geq 0.90, \kappa \leq 0.15 \%$ or $\lambda=1.0, \beta=1.0, \kappa \leq$ $0.32 \%$ or $\lambda=1.0, \beta \geq 0.78, \kappa=0.0 \%$ or $\lambda \geq 0.585, \beta=1.0$, $\kappa=0.0 \%$. The comparison analyses indicated that the testing section from YDK4+439.204 to YDK5+485.316 had a better grouting fill rate and smaller eccentricity ratio of shield tunneling than the section from $Y D K 4+313.504$ to $Y D K 5+552.016$, but the support pressure was not well controlled.

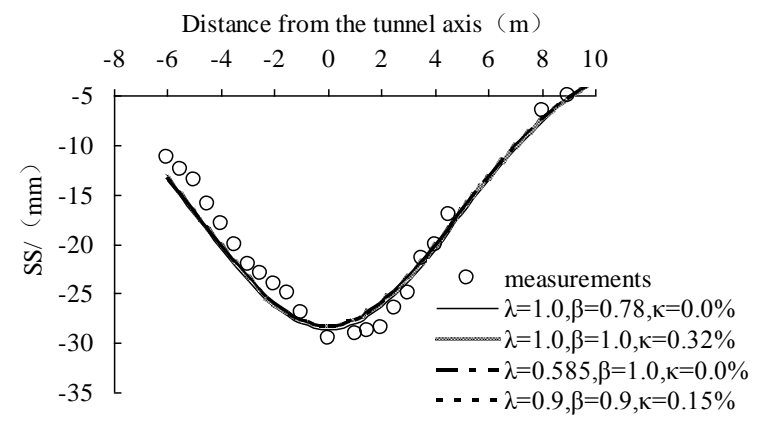

Fig. 5 SS prediction under different STPs

\subsection{Control standards of shield tunneling}

According to the control standards of the SS proposed by geotechnical experts and based on engineering experiences in China, the maximum SS of the center of the metro tunnel was not allowed to reach over $30.0 \mathrm{~mm}$ for the safety of ground structures and pavements. The damage classifications of masonry structures based on the value of surface deformation, including incline, curvature, and horizontal deformation, are regulated by the Ministry of Coal Industry of PRC (2000).

In other countries, the general control standards are relaxed to $50.0 \mathrm{~mm}$, the slope of the inflection point of SS is not allowed to exceed to $1 / 300$ (or 3.3\%), and the maximum of the coefficient of volume loss is less than $5.0 \%$.

Given the control standards and modified Peck formula Eq. (12), the maximum SS can be expressed as follows:

$$
S_{\max }=\frac{\sqrt{\pi}\left(4 g R+g^{2}\right)}{4 \sqrt{2} i}=\frac{0.313\left(4 g R+g^{2}\right)}{K H}
$$

The point of the largest slope of the settlement curve occurred when $x$ is equal to the settlement trough width $i$ (or $x=i$ ), which is given by

$$
s^{\prime}(x=i)=\frac{d s}{d x}=\frac{-s_{\max } x}{i^{2}} \exp \left[\frac{-x^{2}}{2 i^{2}}\right]=\frac{0.19\left(4 g R+g^{2}\right)}{(K H)^{2}}
$$

The point of the maximum surface curvature occurs when $x$ is zero (or $x=0$ ), which can be calculated as

$$
s^{\prime \prime}(x=0)=\frac{d^{2} s}{d x^{2}}=\frac{s_{\max }}{i^{2}}\left[\frac{x^{2}}{i^{2}}-1\right] \exp \left[\frac{-x^{2}}{2 i^{2}}\right]=-\frac{0.313\left(4 g R+g^{2}\right)}{(K H)^{3}}
$$

The gap parameters can be calculated using Eq. (11), with values of $H=16.5 \mathrm{~m}, K=0.49$, and $R=3.125 \mathrm{~m}$. Taking the testing section from YDK4+313.504 to $Y D K 5+552.016$ of Xi'an subway line No. 2 as an example, the analysis parameters can be obtained from Section 2.6. The above equations can be expressed as Eq. (16)

$$
\left\{\begin{array}{l}
\frac{0.313\left(4 g R+g^{2}\right)}{K H} \leq 0.03 \\
\frac{0.19\left(4 g R+g^{2}\right)}{(K H)^{2}} \leq 3.0 \%[[\mathrm{I}], 6.0 \%[\mathrm{II}] \\
\frac{0.313\left(4 g R+g^{2}\right)}{(K H)^{3}} \leq 0.2 \times 10^{-3}[\mathrm{I}], 0.4 \times 10^{-3}[\mathrm{II}]
\end{array}\right.
$$

From Eq. (16), the gap parameters can be calculated when the damage classification is I or II. The gap parameters are obtained by solving the above equations:

$$
\text { I : }\left\{\begin{array}{l}
0.0 \leq g \leq 0.0617 m \\
0.0 \leq g \leq 0.0820 m ; \\
0.0 \leq g \leq 0.0270 m
\end{array} \quad \text { II }:\left\{\begin{array}{l}
0.0 \leq g \leq 0.0617 m \\
0.0 \leq g \leq 0.1630 m \\
0.0 \leq g \leq 0.0538 m
\end{array}\right.\right.
$$

From the results of Eq. (17), the control standards of surface curvature are stricter than the maximum SS and slope of SS. Notably, we emphasize both the maximum SS and the surface curvature attributed to the settlement for the safety of ground structures and pavements. Through back analyses of gap parameters according to Eq. (12), the STPs $\kappa, \beta$, and $\lambda$ can be obtained and are shown in Table 2.

Table 2 Control parameters of shield tunneling under damage classifications I and II

\begin{tabular}{cc}
\hline $\begin{array}{c}\text { Control } \\
\text { parameters }\end{array}$ & Damage classification I $\quad$ Damage classification II \\
\hline Case (1) & $\beta \geq 0.84 ; \kappa=0.0 \% ; \lambda=1.00 \quad \beta \geq 0.67 ; \kappa=0.0 \% ; \lambda=1.00$ \\
Case (2) & $\beta=1.00 ; \kappa \leq 0.25 \% ; \lambda=1.00 \beta=1.00 ; \kappa \leq 0.49 \% ; \lambda=1.00$ \\
Case (3) & $\beta=1.00 ; \lambda \geq 0.76 ; \kappa=0.0 \% \quad \beta=1.00 ; \lambda \geq 0.69 ; \kappa=0.0 \%$ \\
Case (4) & $\beta \geq 0.92 ; \kappa \leq 0.10 \% ; \lambda \geq 0.92 \beta \geq 0.85 ; \kappa \leq 0.20 \% ; \lambda \geq 0.85$ \\
\hline
\end{tabular}

As shown by the back analysis results in Table 2, the surface deformation of damage classification should be kept within level I to ensure structural security in the city. The control standards of STPs may be set as follows: $\beta \geq 0.92, \kappa \leq 0.10 \%$, and $\lambda \geq 0.92$, and the maximum SS may be less than $15.0 \mathrm{~mm}$. When the damage classification is at level II, the control standards should be limited as follows: $\beta \geq 0.85, \kappa \leq 0.20 \%$, and $\lambda$ $\geq 0.85$, and the maximum SS may be less than 28.0 $\mathrm{mm}$.

\section{CONCLUSIONS}

(1) The SS induced by shield tunneling method can be predicted using the modified Peck formula based on 
the modified gap parameters proposed in this study. The modified gap parameters with consideration of shield tunneling technology can be expressed with the support pressure ratio of shield $(\lambda)$, fill rate of grouting $(\beta)$, and eccentricity ratio of shield $(\kappa)$. The fill rate of grouting has a minimal effect on SS, support pressure ratio has a significant influence on SS, and eccentricity ratio has the maximum effect on SS.

(2) The control standards using the method of maximum SS may be inadequate for the safety of the surrounding masonry structures and pavements. The maximum surface curvature should also be considered given that it is obviously stricter than the former.

(3) The control standards of shield tunneling technology can be obtained through the back analysis of damage classification. In the ancient city of Xi'an, the surface deformation of damage classification should be retained within level I, and the parameters of shield tunneling technology are suggested as: $\beta \geq 0.92, \kappa \leq$ $0.10 \%$, and $\lambda \geq 0.92$. The maximum SS may be less than $15.0 \mathrm{~mm}$. If the damage classification is at level II, the control standards of should be limited as: $\beta \geq 0.85$, $\kappa \leq 0.20 \%$, and $\lambda \geq 0.85$. The maximum SS may be less than $28.0 \mathrm{~mm}$.

\section{ACKNOWLEDGMENTS}

Financial supports from the Natural Science Foundation of China (Grant No. 51308456), and from the Project of Scientific Research of Shaanxi (Grant No. 2013JQ7022 and 2015JM5175) are gratefully acknowledged. The authors acknowledge thoughtful and helpful comments from the reviewers.

\section{REFERENCES}

1) Attewell, P. B. Ground movements caused by tunneling in soil. Conference on Large Ground Movements and Structures, Cardiff, London: Pentech Press, 1978: 812-948

2) Attewell, P. B., Glossop, N. H., and Farmer, I. W. Ground deformations caused by tunnelling in soil. Ground Engineering, 1978, 15(8):32-41

3) Attewell, P. B. and Woodman, J. P. Predicting the dynamics of surface settlement and its derivatives caused by tunnelling in soil. Ground engineering, 1982, 15(8): 13-20, 36.

4) Attewell, P. B., Yeates, J., and Selby, A. R. Soil movements induced by tunnelling and their effects on pipelines and structures. Blackie, Glasgow, 1986.

5) Broms, B. B. and Bennermark, H. Stability of clay at vertical openings. ASCE Journal of Soil Mechanics and Foundation Engineering Division SM, 1967, 193: 71-94

6) Burland, J. B., Standing, J. R. and Jardine, F. M. Assessing the risk of building due to tunnelling lessons from the Jubilee Line Extension, London. Geotechnical Engineering: meeting society needs. Proc. of the fourth Southeast Asian geotechnical conf. held Hong Kong. Dec. 2001. (eds: K.K.S. Ho and K.S. Li.), 2001: 17-44

7) Celestino, T. B., Gomes, R. A. M. P, and Bortolucci, A. A. Errors in ground distortions due to settlement trough adjustment. Tunnelling and underground space technology, 2000,15(1): 97-100.
8) Glossop, N. H. Ground movements caused by tunnelling in soft soils. PhD Thesis, University of Durham, 1978.

9) Lee, K. M. and Rowe, R. K. Subsidence due to tunnelling: Part II -Evaluation of a prediction technique. Canadian Geotechnical Journal, 1992, 29(5): 941-954.

10) Loganathan, N. and Poulos, H.G. Analytical prediction for tunneling-induced ground movements in clays. Jnl. Geot. And Geoenv. Eng., ASCE, 1998,124(9):846-856

11) Lo, K,Y., Ng, M. C., and Rowe, R. K., Predicting settlement due to tunneling in clays, ASCE, Geotech III Conference, Atlanta,GA, 1984B, 46-76 Sagaseta, C. Analysis of undrained soil deformation due to ground loss.Geotechnique. 1987, 37( 3):301-320

12) Mair, R. J., Taylor, R. N., and Bracegirdle, A. Subsurface settlement profiles above tunnels in clays. Geotechnique. 1993, 43(2): 315-320.

13) Mair, R. J., and Taylor, R. N. Bored tunneling in the urban environment. //Proceedings of the Fourteenth International Conference on Soil Mechanics and Foundation Engineering. Hamburg: Balkema A A, 1997: 2353-2380.

14) O'Reilly, M. P., and New, B. M. Settlements above tunnels in the United Kingdom-their magnitude and prediction. Proc. Tunnelling 82, Institution of Mining and Metallurgy, London, 1982: 173-181

15) Peck, P. B. Deep excavations and tunneling in soft ground .Proceedings of the 7th International Conference on Soil Mechanics and Foundation Engineering. Mexico City: Sociedad Mexicana de Mecanica de Suelos A C,1969, 225-290

16) Rankin, W. J. Ground movement resulting from urban tunnelling: predictions and effects. Engineering geology of underground movements. Proc. of the 23rd annual conf of the eng. group of the Geological Society held at Nottingham University. Bell et al eds., 1988: 79-92.

17) Rowe, R. K., Lo, K. Y. and Kack, G. J. A method of estimating surface settlement above tunnels constructed in soft ground. Canadian Geotechnical Journal, 1983, 20 (8) : $11-22$

18) Schmidt, B. Settlements and ground movements associated with tunneling in soils, PhD Thesis, University of Illinois, Urbana, 1969.

19) State Coal Industry Administration. Regulations for buildings, waters, railways and the coal pillar design and mining of the main mine working. Beijing: coal industry publishing house, 2000.(In Chinese)

20) Verruijt, A. and Booker, J. R. Surface settlements due to deformation of a tunnel in an elastic half plane, Geotechnique. 1996,46 (4):753-756

21) Yang, J. S. and Liu, B. C. Ground surface movement and deformation due to tunnel construction by squeezing shield, Rock and soil mechanics, 1998, 19(3):10 13(In Chinese) 